\title{
Do dentists practice what they know? A cross-sectional study on the agreement between dentists' knowledge and practice in restoring endodontically treated teeth
}

\author{
Rua S. Babaier ${ }^{1,3^{*}}$ and Sumaya O. Basudan ${ }^{2}$
}

\begin{abstract}
Background: There are very few studies comparing dentists' knowledge in relation to their clinical approach despite the existence of a possible gap between what they know and what they do.

Aim: To measure the agreement between knowledge and practice methods related to a selected clinical scenario involving the placement of an indirect post in endodontically treated teeth (ETT) among different types of practitioners.

Methods: An electronic questionnaire was emailed to members of the Saudi Dental Society. The questionnaire presented a clinical scenario of restoring a posterior ETT with an indirect post, core unit, and crown, followed by specific questions regarding knowledge and practice related to ten different treatment aspects such as who prepares the post space, technique, isolation, time, gap between gutta-percha, and time to cementation of the crown. Each question was presented twice for each aspect, once asking about their practice method and then what they thought was the correct practice (knowledge). The relationship between the participants' responses and their specialty and the agreement between the responses of knowledge and practice for each participant were analyzed by Pearson's chi-square test and Kappa.

Results: 203 completed questionnaires were analyzed. Most participants were 30 years old or younger (62.6\%), and general dental practitioners (59\%). When comparing the knowledge to the practice methods of each participant, nine out of ten aspects were of a "weak" level agreement or below (kappa $<0.59, p<0.001$ ). Only one aspect demonstrated a "strong" level of agreement (Kappa $=0.804$ ), which was related to the duration of time between obturation and post space preparation in the presence of a periapical lesion. However, this strong agreement in the responses was not aligned with current evidence. There was also a significant difference among the responses of endodontists, restorative dentists and general practitioners in most of the aspects.
\end{abstract}

Conclusion: Overall, there was a weak agreement between what practitioners know and do in most aspects of a selected clinical scenario involving the placement of an indirect post in posterior ETT. Moreover, the participant's specialty influenced their responses regarding both knowledge and clinical practice.

Keywords: Patient care, Practice gap, Evidence-based dentistry, Post and core, Root canal therapy, Post space

\footnotetext{
*Correspondence: rbabaier@ksu.edu.sa

${ }^{1}$ Department of Prosthetic Dental Sciences, College of Dentistry, King

Saud University, Riyadh 12372, Saudi Arabia

Full list of author information is available at the end of the article
} original author(s) and the source, provide a link to the Creative Commons licence, and indicate if changes were made. The images or other third party material in this article are included in the article's Creative Commons licence, unless indicated otherwise in a credit line to the material. If material is not included in the article's Creative Commons licence and your intended use is not permitted by statutory regulation or exceeds the permitted use, you will need to obtain permission directly from the copyright holder. To view a copy of this licence, visit http://creativecommons.org/licenses/by/4.0/. The Creative Commons Public Domain Dedication waiver (http://creativeco mmons.org/publicdomain/zero/1.0/) applies to the data made available in this article, unless otherwise stated in a credit line to the data. 


\section{Background}

The restorative treatment options for posterior teeth that undergo root canal treatment (RCT) vary in complexity from a minimal filling to an indirect post and crown. The reported success rate of endodontically treated teeth (ETT) is high; however, the treatment outcome depends on the quality of not only the endodontic treatment but also the coronal restoration. Therefore, it has become important to investigate the different treatment philosophies and practices related to this topic among dentists with various backgrounds [1-5].

Survey-based studies are a valuable tool for identifying the levels of knowledge, attitudes, and practices of clinicians, highlighting the adherence of practitioners to current recommendations or best practices. Earlier surveys evaluated prosthodontic-related aspects among clinicians such as the need for cuspal coverage, ferrule effect, the rationale for post-placement and technique for post space preparation (PSP), remaining apical seal, and types of posts, cement and core materials [6-13]. While RCT and subsequent restorative treatment can be performed by a general dental practitioner (GDP) or a more specialized practitioner such as an endodontist or a restorative specialist, an overlap exists between the different disciplines during PSP, since any of the groups can prepare it. Their expertise or specialization may influence the approaches and treatment decisions of practitioners. Leakage, for example, especially coronally, is detrimental to the success of ETT and maybe a major concern during different steps of treatment [14]. However, there is limited knowledge of different practitioners' perspectives and approaches towards the multiple aspects of PSP.

Surveys on the restorative management of ETT have investigated clinicians' knowledge of certain treatment aspects or their clinical practices [6-13]. However, both knowledge and practice have not been studied simultaneously or compared. Although knowledge and practice should ideally be in agreement, the literature has demonstrated that in health care, a gap between knowledge "know-what" and practice "do" may exist [15]. Most commonly, this gap has been explored through the "Knowledge Translation" model which is described as "a dynamic and iterative process that includes the synthesis, dissemination, exchange and ethically-sound application of knowledge to improve the health of Canadians, provide more effective health services and products and strengthen the healthcare system" [16, 17]. Accordingly, discrepancies in knowledge and practice can be explained by the difficulties practitioners face in knowledge application. We investigate here if such a gap does indeed exist in the management of ETT. To the best of our knowledge, there are no studies that have compared dentists' knowledge to their clinical approach.
Therefore, the aim of this study is twofold:

1. To measure the agreement between knowledge and practice methods related to a selected clinical scenario involving indirect post-placement in posterior ETT.

2. To compare the knowledge and practice responses between the different types of practitioners.

\section{Methods}

The research protocol was in accordance with the principles of the World Medical Association Declaration of Helsinki and was approved by the Institutional Review Board and the College of Dentistry Research Center. A self-administered web-based questionnaire was created on a survey website www.FreeOnlineSurveys.com and emailed to the Saudi Dental Society (SDS). This official scientific society includes around 2500 active members from the dental field, such as dentists, dental assistants, technicians, hygienists, and dental students [18]. To reach out for our target participants, a covering letter invited dental practitioners involved in ETT management, including GDPs, endodontists, and restorative specialists such as prosthodontists and operative specialists. The objective of the survey and contact information of the researchers were included in the informed consent. Anonymity and confidentiality were assured, along with the voluntary nature of study participation. Responses were collected over two months, with an email reminder sent three weeks after the first request. There was no accurate data on the number of each specialty category within the SDS system. Therefore, the sample size was estimated based on the number of all active SDS members to be 250 with a confidence level of $95 \%$ and $5 \%$ error margin.

The questionnaire draft was derived from published studies and guided by experts' opinions (GDPs, Restorative specialists, and Endodontists) [7, 8, 10, 11]. The experts and skilled biostatistician evaluated face and content validity. The questionnaire was then piloted and adjusted for clarity. Reliability was calculated to be 0.75 (See Additional file 1: Supplementary file). The questionnaire was composed of the following three parts: part one was related to the demographic information of the participants; part two was related to the need and frequency of the placement of coronal cuspal restorations on ETT, which was answered on a sliding bar from 0 to 100; and part three addressed specific issues related to a clinical scenario for restoring posterior ETT in which an indirectly fabricated post, core unit, and crown were indicated without a need for a crown lengthening procedure. The responses to questions on the frequency of post and crown placement in posterior ETT were categorized as 
follows: rarely: $0-20 \%$, sometimes: $30-50 \%$, and more frequently: $60-100 \%$. The clinical case presented a selected restorative treatment with a specific approach to standardize different possible variables aiming to examine the participants' philosophies more closely on a case with limited options regardless of other best treatment options. Multiple-choice questions were related to the time and method of preparation, remaining gutta-percha, presence of periapical lesions, practitioner preparing the post space, and presence of gaps, isolation, and temporization.

Each aspect was presented as two questions: the first question addressed how the participant manages a specific clinical situation (practice). The second was what the participant thought was the best way to handle the same situation (knowledge). For example, the questions for aspect \#2 in the questionnaire were as follows:

- Do you routinely apply a rubber dam during post space preparation?

- Do you think it is recommended to place a rubber dam during post space preparation routinely?

\section{Data analysis}

The data were analyzed using Statistical Package for Social Sciences software, version 21.0 (IBM Corp., New York, USA). Descriptive statistics (frequencies and percentages) were used to describe the categorical variables. Pearson's chi-square test was used to analyze the relationship of the participants' responses to their specialty, years of experience, and workplace. Kappa statistics were computed to observe the agreement between the responses of knowledge and practice aspects for each participant. Strength of agreement was interpreted following McHugh [19]: 0-0.20, none; 0.21-0.39, minimal; $0.40-0.59$, weak; $0.60-0.79$, moderate; $0.80-0.90$, strong; and above 0.90 , almost perfect. Statistical significance was set at $0.05(p \leq 0.05)$.

\section{Results}

\section{Demographics}

Of the returned questionnaires, 44 were excluded either because they were incomplete or because the participants were not involved in the restoration of ETT (e.g., dental hygienists and orthodontists), which resulted in 203 completed questionnaires. The response rate could not be calculated since the original number of SDS members eligible to participate unknown. Of the 203 participants, $127(62.6 \%)$ were aged 30 years or younger, $56(27.6 \%)$ were between 31 and 40 years, and 20 (9.9\%) were older than 40 years. There were more females $(67 \%)$ and participants of Saudi nationality (85.2\%) than any other group. There were more GDPs $(n=120)$, than Restorative Specialists $(n=68)$ or Endodontists $(n=15)$. Figure 1 presents the distribution of participants according to specialty, years of experience and working sector.

\section{General restorative management of posterior ETT}

There was a general tendency towards providing cuspal protection to teeth with root canal treatment among the different participants. However, specialists placed crowns more frequently on posterior ETT than GDPs (Table 1).

\section{Agreement between knowledge and practice}

The agreement levels between the knowledge and practice responses of the participants were statistically significant in all aspects $(p<0.05)$ (Table 4$)$. Of the ten treatment aspects comparing each participant's knowledge and practice responses, none demonstrated "almost perfect" agreement. In contrast, only one (aspect \#7, the time of PSP after obturation in the presence of a periapical lesion (PA) demonstrated a "strong" level of agreement. The remaining aspects showed either weak or minimal agreement levels $(p<0.0 .53)$ (aspects \#1, 3, 5, 6, and 9) or no agreement between knowledge and practice $(\# 2,4,8$, and 10) (Table 4).

\section{Differences between practitioners in the technical management of ETT}

Table 2 shows the different participants' responses towards the technical management of restoring ETT; statistically significant differences were observed. A high proportion of endodontists (93.3\%) believed that the clinician who performed the RCT is the best clinician to prepare the post space, as did $64.6 \%$ of restorative specialists and $42.5 \%$ of GDPs $(p=0.001)$.

Participants reported that a rubber dam should be routinely placed during PSP without any statistically significant difference across practitioner type $(p=0.374)$; however, in practice, endodontists put them routinely significantly more than the other practitioners $(p<0.001)$.

\section{Differences between practitioners in time-related aspects}

Overall, most of the responses favored decreasing the time duration between the different treatment steps. However, there was a statistically significant difference in practitioners' responses from other disciplines concerning the time interval for restoring an ETT that requires post-placement (Table 3).

Restorative specialists and endodontists preferred to prepare the post space immediately or shortly following obturation compared with GDPs. If a periapical lesion was present, endodontists significantly $(p<0.001)$ preferred immediate PSP compared with the other groups, who delayed it until there was evidence of healing. 


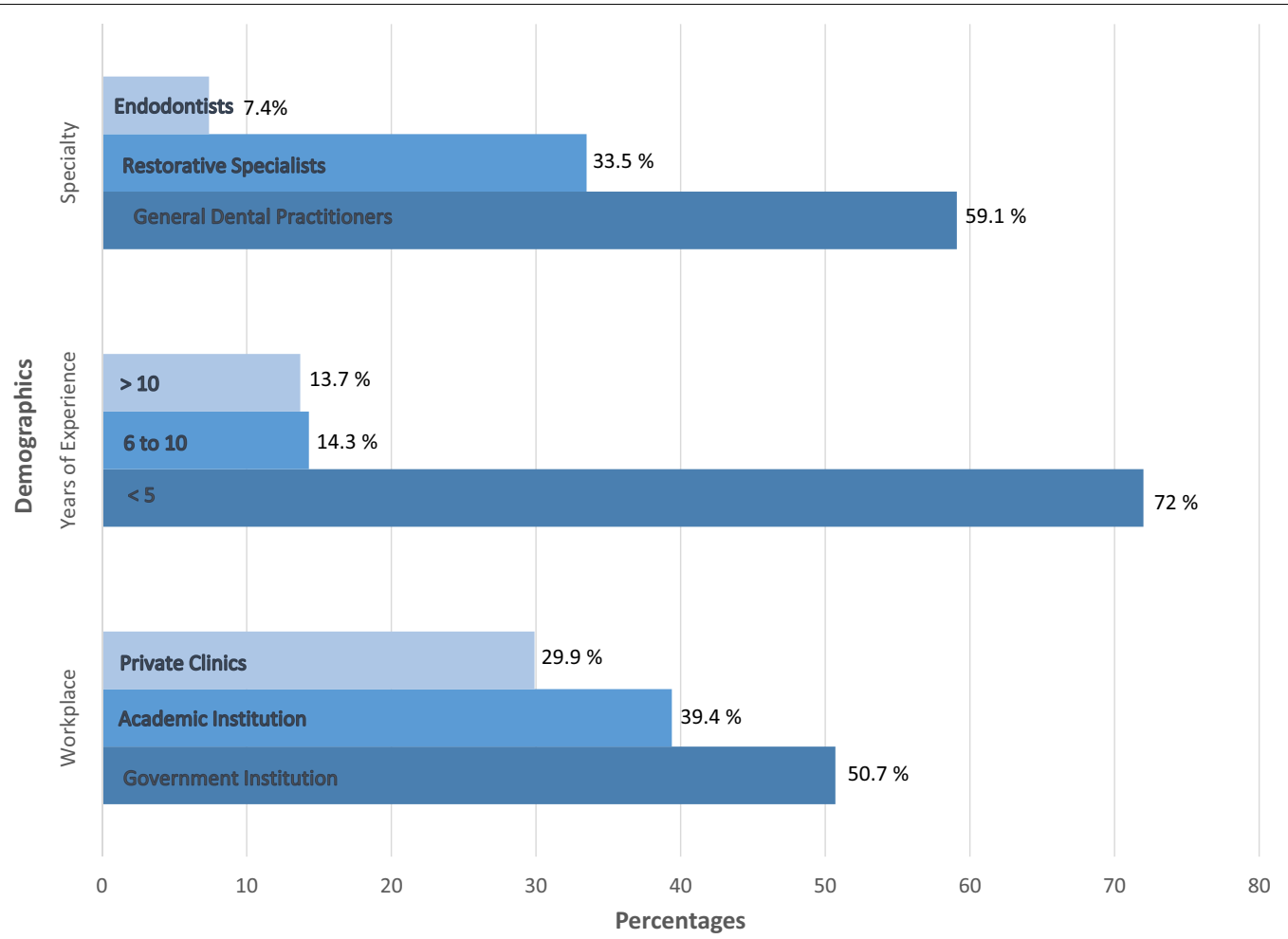

Fig. 1 Distribution of sociodemographic characteristics of a sample of Saudi dentists $(n=203)$

Table 1 Association between the responses towards the general restorative management of the posterior ETT and the specialty of a sample of Saudi dentists $(n=203)$

\begin{tabular}{lccc}
\hline $\begin{array}{l}\text { General restorative } \\
\text { management of posterior ETT }\end{array}$ & \multicolumn{3}{l}{ Specialty $\mathrm{n}(\%)$} \\
\cline { 2 - 4 } GDP & \multicolumn{2}{c}{ Resto } & Endo \\
\hline $\begin{array}{l}\text { Frequency of crowning } \\
\text { Rarely }\end{array}$ & $7(5.8)$ & $1(1.5)$ & 0 \\
Sometimes & $31(25.8)$ & $6(8.8)$ & $2(13.3)$ \\
More frequently & $82(68.3)$ & $61(89.7)$ & $13(86.7)$ \\
The need for cuspal coverage on all posterior ETT & & \\
Rarely & $8(6.6)$ & $6(8.8)$ & $1(6.7)$ \\
Sometimes & $39(32.5)$ & $4(5.9)$ & $1(6.7)$ \\
More frequently & $73(60.8)$ & $58(85.3)$ & $13(86.7)$ \\
Frequency of post-placement & & & \\
Rarely & $33(27.5)$ & $7(10.3)$ & $8(53.3)$ \\
Sometimes & $44(36.7)$ & $21(30.9)$ & $4(26.7)$ \\
More frequently & $43(35.8)$ & $40(58.8)$ & $3(20.0)$ \\
\hline
\end{tabular}

GDP general dental practitioner, Resto. restorative specialist, Endo. Endodontist, PSP post space preparation, ETT endodontically treated teeth; Rarely: 0-20\%; Sometimes: $30-50 \%$; More frequently: $60-100 \%$

\section{Effect of years of experience and workplace}

The results showed no statistically significant differences in the relationship between the participants' responses (knowledge and practice) and years of experience or work sector for most of the above aspects. There was a statistically significant difference only in considering the routine application of a rubber dam during PSP. Nearly $71 \%$ of participants with less than five years of experience adopted this isolation concept compared with participants with more experience (6-10 years, $54.2 \%$ and more than ten years, $43.5 \%)\left(X^{2}=7.87, p=0.02\right)$.

\section{Discussion}

\section{Agreement between knowledge and practice}

This study measured the consistency in participants' responses between knowledge and practice aspects based on a presented case that required restorative management of ETT with an indirect post and core unit, followed by a crown. Nine out of ten aspects in the questionnaire showed "weak" agreement levels and below. The agreement was measured using intrarater reliability instead of comparing the total responses of the participants. Therefore, although the total numbers of the selected answers in practice and knowledge may be similar, there was disparity among the individual participants who selected these answers, resulting in minimal agreement (0.34), as observed in aspect \#5 (Table 4). Conversely, in aspect \#7, the participants' responses for both knowledge and practice were consistent, which resulted in strong agreement 


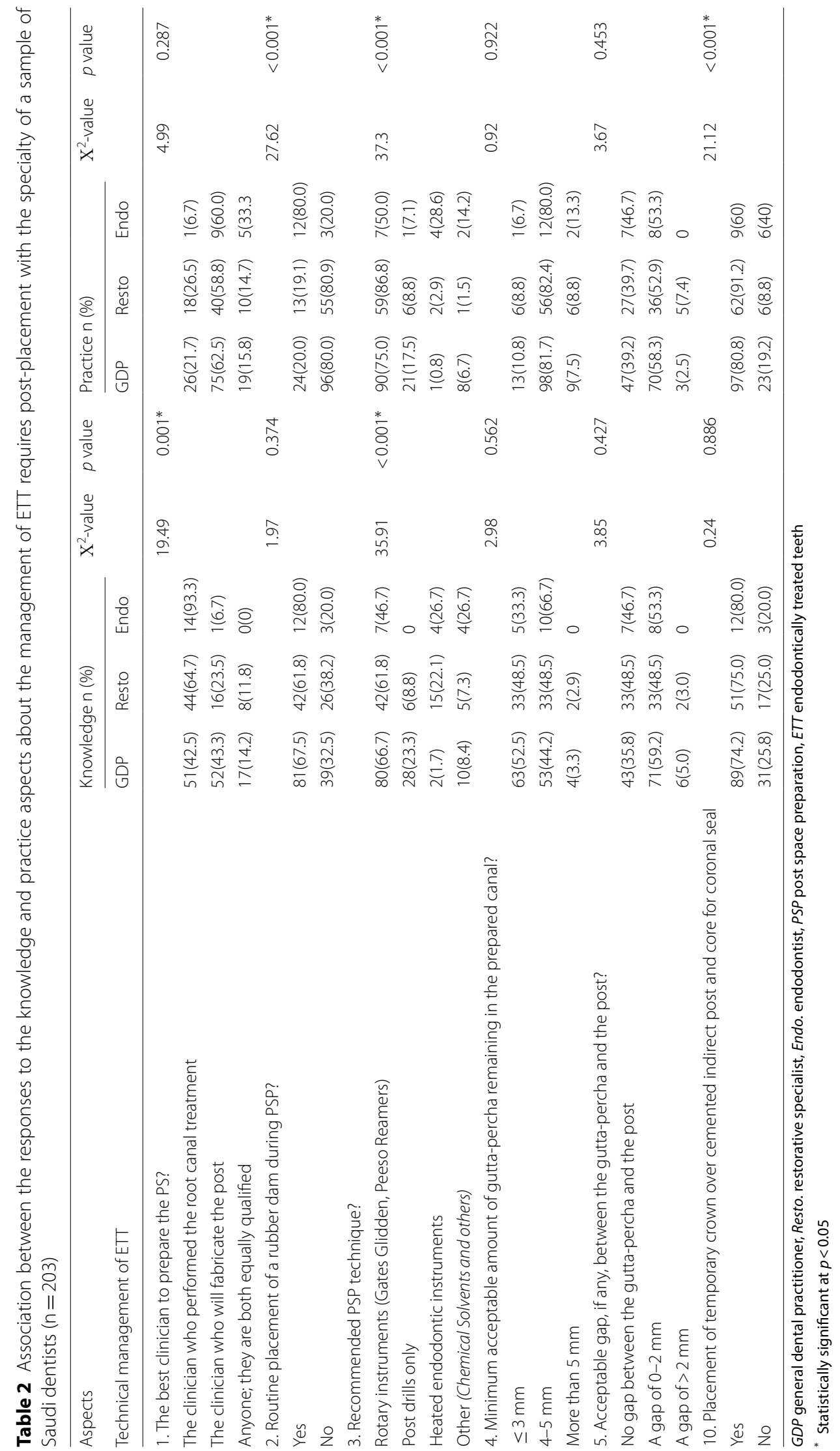




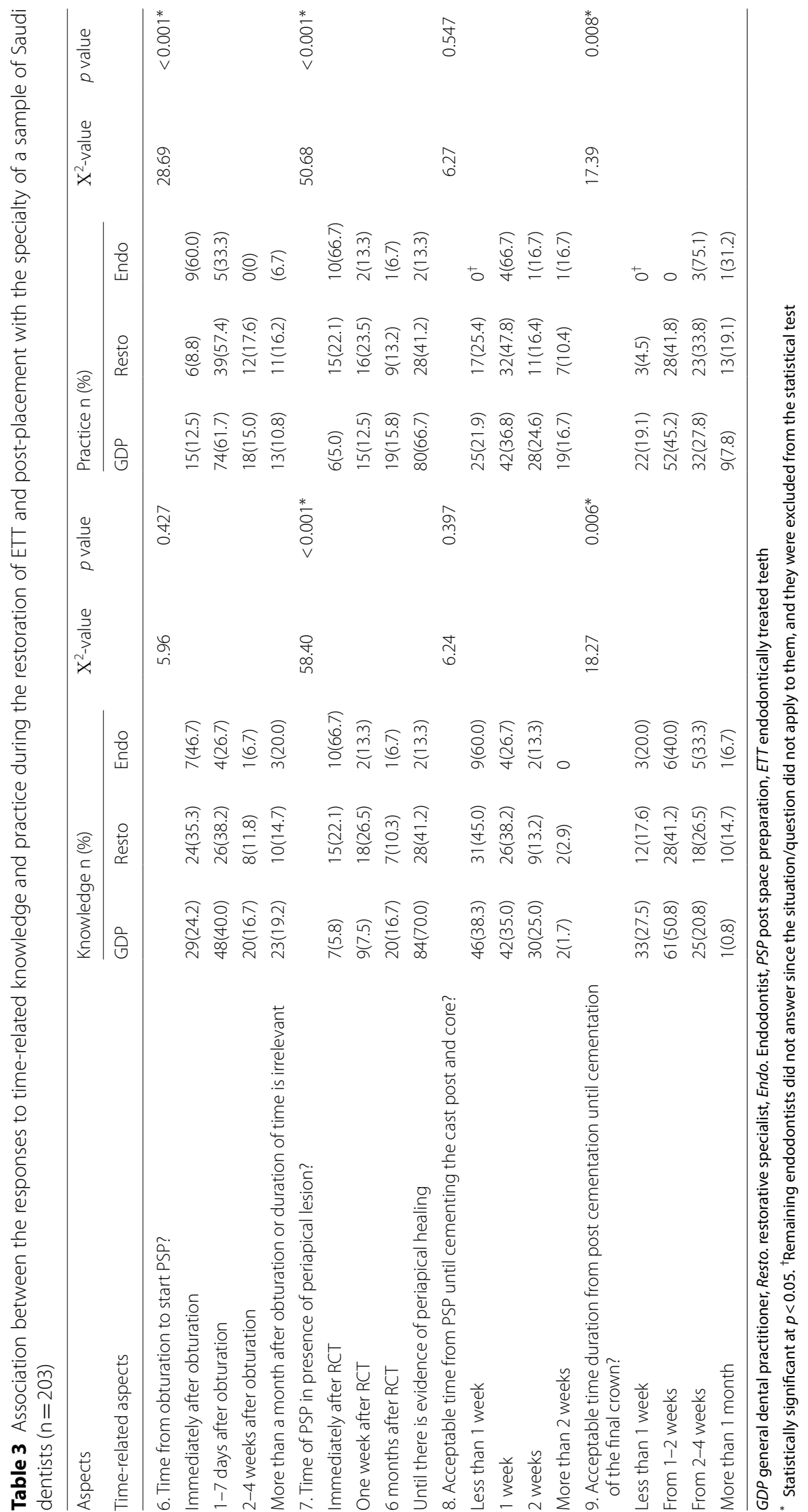


Table 4 Comparison of knowledge and practice answers and agreement levels among a sample of Saudi dentists $(n=203)$

\begin{tabular}{|c|c|c|c|}
\hline Aspects & Knowledge answers & Practice answers & Agreement* level \\
\hline Technical management of ETT & n (\%) & & \\
\hline 1. The best clinician to prepare the post space? & & & 0.306 \\
\hline The clinician who performed the root canal treatment & $109(53.7)$ & $45(22.2)$ & Minimal \\
\hline The clinician who will fabricate the post & $69(34.0)$ & $124(61.1)$ & $p<0.001$ \\
\hline Anyone, they are both equally qualified & $25(12.3)$ & $34(16.7)$ & \\
\hline 2. Routine placement rubber dam during post space preparation? & & & 0.192 \\
\hline Yes & $135(66.5)$ & $49(24.1)$ & None \\
\hline No & $68(33.5)$ & $154(75.9)$ & $p<0.001$ \\
\hline 3. Recommended post space preparation technique? & & & 0.521 \\
\hline Rotary instruments (Gates Glidden, Peeso Reamers) & $129(63.9)$ & $156(77.2)$ & Weak \\
\hline Post drills only & $34(16.8)$ & $28(13.9)$ & $p<0.001$ \\
\hline Heated endodontic instruments & $21(10.4)$ & $7(3.5)$ & \\
\hline Other (Chemical Solvents and others) & $18(8.9)$ & $11(5.4)$ & \\
\hline 4. Minimum acceptable amount of gutta-percha remaining in the prepared canal? & & & 0.176 \\
\hline$\leq 3 \mathrm{~mm}$ & $101(49.8)$ & $20(9.9)$ & None \\
\hline $4-5 \mathrm{~mm}$ & $96(47.3)$ & $166(81.8)$ & $p<0.001$ \\
\hline More than $5 \mathrm{~mm}$ & $6(3.0)$ & $17(8.4)$ & \\
\hline 5. Acceptable gap, if any, between the gutta-percha and the post? & & & 0.344 \\
\hline No gap between the gutta-percha and the post & $81(39.9)$ & $83(40.9)$ & Minimal \\
\hline A gap of 0 to $2 \mathrm{~mm}$ & $114(56.1)$ & $112(55.2)$ & $p<0.001$ \\
\hline A gap of $>2 \mathrm{~mm}$ or presence of a gap does not matter & $8(3.9)$ & $8(3.9)$ & \\
\hline \multicolumn{4}{|l|}{ Time-related aspects } \\
\hline 6. Time from obturation to start preparing the post space? & & & 0.438 \\
\hline Immediately after obturation & $30(14.8)$ & $60(29.6 \%)$ & Weak \\
\hline 1-7 days after obturation & $118(58.1)$ & $78(38.4 \%)$ & $p<0.001$ \\
\hline 2-4 weeks after obturation & $30(14.8)$ & $29(14.3 \%)$ & \\
\hline More than a month after obturation or duration of time is irrelevant & $25(12.3)$ & $36(17.7 \%)$ & \\
\hline 7. Time of PSP in presence of periapical lesion & & & 0.804 \\
\hline Immediately after RCT & $32(15.8)$ & $31(15.3)$ & Strong \\
\hline One week after RCT & $29(14.3)$ & $33(16.3)$ & $p<0.001$ \\
\hline 6 months after RCT & $28(13.8)$ & $29(14.3)$ & \\
\hline Until there is evidence of periapical healing & $114(56.2)$ & $110(54.2)$ & \\
\hline 8. Acceptable time from PSP until cementing the indirect post and core? & & & 0.128 \\
\hline Less than 1 week & $79(42.2)$ & $42(22.5)$ & None \\
\hline 1 week & $66(35.3)$ & $78(41.7)$ & $p=0.003$ \\
\hline 2 weeks & $38(20.3)$ & $40(21.4)$ & \\
\hline More than 2 weeks & $4(2.1)$ & $27(14.4)$ & \\
\hline 9. Acceptable duration from post cementation until cementation of the final crown? & & & 0.301 \\
\hline Less than one week & $44(23.7)$ & $25(13.4)$ & Minimal \\
\hline From 1-2 weeks & $89(47.8)$ & $80(43.0)$ & $p<0.001$ \\
\hline From 2-4 weeks & $42(22.6)$ & $58(31.2)$ & \\
\hline More than one month & $11(5.9)$ & $23(12.4)$ & \\
\hline 10. Placement of temporary crown over cemented post and core for coronal seal & & & 0.156 \\
\hline Yes & $152(74.9)$ & $165(83.1)$ & None \\
\hline No & $51(25.1)$ & $38(18.7)$ & $p=0.024$ \\
\hline
\end{tabular}

PSP post space preparation, ETT:endodontically treated teeth, $R C T$ root canal treatment

* Agreement value measured by kappa statistics 
(0.804). This analysis provided valuable insight into the differences in each participant's attitudes towards a single clinical decision.

There are few reports from healthcare literature on the discrepancy between what is known and what is done. For example, Khan et al. demonstrated that students may be knowledgeable of the shortened dental arch as a treatment concept but rarely implement it in clinical practice [20]. In obstetrics and gynecology, Wilder et al. found that although most obstetricians are aware of pregnancy and periodontal disease interrelationships, they rarely address such issues during patient care [21]. This difference has often been explained through knowledge translation, which hypothesizes that practice is a translation of knowledge, and knowledge is acquired first and then applied over time [22]. Therefore, factors that affect this process at any step may contribute to the gap. Adams et al. estimated this gap in following medical guidelines to be approximately $27 \%$. Several researchers have explored the gap and its related elements [23]. In their informative and comprehensive review, Afrashtehfar and Assery discussed the challenges a dentist faces in practicing evidence-based dentistry. Some of the issues are related to restrictions in accessing relevant information and its critical assessment and the absence of an applicable model to permit a clinical shift and subsequent integration, and finally, patient hindrance limitations [16]. Majumdar et al. categorized the barriers to applying evidence to clinical care into four main categories: evidence, clinician, patient and setting [15]. To demonstrate this, participants' answers to aspect \#7, which was related to the duration of time between obturation and PSP in the presence of a PA, demonstrates a barrier in "evidence", despite the strong agreement (0.804). In cases with a PA lesion, most participants believed and opted for delaying PSP until demonstration of PA healing, which does not follow current recommendations of restoring ETT as soon as possible [24]. This issue with their information or "evidence" was reflected in their practice as well. Examples of barriers during application include information aspect \#2. Most of the participants answered that rubber dam isolation should be applied during PSP as recommended in the literature [25]; however, participants rarely applied this principle. Although being aware of new evidence is a prerequisite to changing practice, gaps or inconsistencies between best practice and daily practice are not entirely a result of knowledge deficits or vice versa. Some participants demonstrated sound clinical practice, while their answers to the related knowledge questions were erroneous. In responding to aspect \#4 regarding the acceptable remaining amount of gutta-percha apically during PSP, half of the participants thought that less than $3 \mathrm{~mm}$ was acceptable, while in practice, only $10 \%$ did so, while the remaining $80 \%$ of the participants left $4-5 \mathrm{~mm}$ of root filling material after PSP in clinical practice, as recommended in the literature $[1,26]$, which does not follow the knowledge translation model. Additionally, in some respects, several options are considered clinically acceptable. Yet, participants' choices were inconsistent in their responses between the knowledge and practice aspects, such as the PSP technique or the time from obturation to start of PSP (aspects \#3 and \#6 in Table 4). Though it was not within this study's scope, it is essential to understand why participants shifted their responses.

Furthermore, this lack of compliance existed despite $72 \%$ of the participants being recent graduates with less than 5 years of experience; one would assume that such new clinicians are likely equipped with the latest evidence. The vital role of education, the impact of curricula, and the role of continuous professional development cannot be overemphasized. However, neither experience nor age showed statistically significant differences in this study, implying that other factors affect the results.

In addition to knowledge, Cabana et al. highlight the role of attitudes and behaviors as barriers to the application, too [27]. The Theory of Planned Behavior has been investigated as a model to explain health care professionals' intention, from different specialties, to apply the same clinical guidelines into practice [28]. Bonetti et al. explored the behavior of dentists. They found that together, intentions and habits, as applied by both the Theory of Planned Behavior and Operant Learning theory, can explain the majority of variance in dentists' clinical behavior [29]. However, further investigations are needed to understand better why dentists practice differently from what they know since each setting is independent.

\section{Differences between practitioners}

Research has repeatedly demonstrated different approaches among different disciplines and between specialists and GDPs [30, 31]. This study focused on the overlapping area between RCT and prosthodontic treatment during PSP, which can be performed by any of the practitioners from the disciplines investigated. The results demonstrated significant differences among the disciplines in several aspects of this study.

For example, specialists favored more conservative and safer options, as demonstrated by the PSP technique's choice. Although all groups favored rotary instruments, the most conservative option was heated instruments, mostly used by endodontists (26.8\%). Interestingly, many studies have indicated no difference in leakage when removing the gutta-percha with a heated or rotary instrument $[1,32,33]$. 
The differences in approach between the different practitioners may become crucial if the approaches are against EBD, e.g., many participants thought it best to wait for evidence of periapical healing before initiating PSP in the presence of a PA lesion. The difference was highly statistically significant between the groups. Most endodontists believed that immediate PSP was best, while most GDPs thought it best to delay treatment until there was evidence of healing. The responses of restorative specialists were equally divided between these two options. Outcome studies of endodontic treatment have determined that an adequate coronal seal is as important as the quality of RCT for success. PAs take several months to many years to heal $[34,35]$; hence, delaying cuspal coverage, even for a few months, results in significantly more ETT failures and fractures [24, 36]. Clinical studies have also demonstrated that the presence of a post did not affect the outcome of ETT in the presence or absence of a PA lesion [2, 37-39]. Additionally, Yee et al. demonstrated that the highest survival in ETT was when the post and core unit were applied within two months after primary RCT, and the crown was placed within 2 months after that [36]. Therefore, placement of a post whenever indicated should not be delayed.

Furthermore, $60 \%$ of endodontists immediately prepared the post space after obturation, while GDPs and restorative specialists delayed PSP from a few days to more than a month. PSP at the time of RCT presents the advantage of easier removal of the root canal filling before it sets, benefiting from working length determination and familiarity with the canal's anatomical characteristics and the already-present rubber dam isolation and minimizing leakage $[1,24,40]$.

Following the indirect post and core cementation, $74.9 \%$ of the study participants thought that the cemented indirect post and core unit alone did not provide an adequate coronal seal. In practice, significantly more restorative specialists (91.2\%) placed temporary crowns than GDPs (80.8\%). Although temporary crowns fulfil other purposes than providing a coronal seal, such as esthetic, functional, and occlusal purposes and proximal stability, prolonged placement of temporary crowns might result in the cement's microleakage jeopardizing the success of RCT. Several studies have shown that the root canal system can become rapidly reinfected in the absence of a satisfactory coronal seal [41, 42].

Overall, for most of the time-related aspects, participants revealed a positive trend following recommended evidence that higher success is achieved when placing a definitive restoration within the minimum treatment duration to minimize the possibility of coronal leakage.

Advances in digital dentistry have promoted restorative treatment in terms of time efficiency and quality
[43]. The use of digital impressions and CAD/CAM fabrication can help the restorative dentist seal the filled root canal system and protect the tooth as soon as possible. A customized post, if indicated, could be designed, milled, and cemented with minimal laboratory steps. Then, a temporary or definitive restoration is fabricated chairside and cemented in the same visit.

This study measured the agreement between dental practitioners' knowledge and practice, which the authors have not found to be addressed in the literature. There were generally poor agreement levels between dentists' knowledge and practice in aspects related to PSP when restoring ETT. These findings highlight that studies investigating participants' knowledge on any issue do not necessarily reflect what the participants may practice, and practice does not reflect knowledge. Further research is needed to identify the reasons behind this disagreement among dental practitioners and address any possible barriers to minimize a care gap.

Additionally, to reduce variation and control the participants' responses, this study's questions were relevant to only one standard clinical scenario that could be treated in any clinical setting. Setting a different clinical scenario with advanced or controversial treatment options may generate different responses from the participants.

The participants' specialty affected both their knowledge and their clinical practice; however, the disagreements between knowledge and practice were demonstrated among all groups in this sample. This finding highlights the importance of a multidisciplinary approach in managing cases and periodically updating dentists in aspects of other specialties that directly affect their practice, which might improve the success rate of dental treatment [44]. Unfortunately, further analysis of agreement among the different practitioners was not possible due to the small number of participating endodontists. Although, the number of each subgroup could not be retrieved accurately from the SDS archives, the distribution of the different specialties within our sample was similar to that of the Saudi dental population [45]. The numbers of participating clinicians practising in private clinics, and those above the age of 40, were also low and need to be addressed in the future. The lower age might represent the age of the members in the society, or the enthusiasm of younger professionals to participate. Nevertheless, the correlation of the participants' age and their responses was investigated, and no statistical significance was found. Finally, it is also important to acknowledge that the results are as accurate as the participants' responses and may be influenced by a bias response bias. 


\section{Conclusion}

Within the limits of our study and based on the participants' responses to questions on a selected clinical scenario involving an indirect post-placement in posterior ETT:

1. Only one out of ten aspects showed strong agreement between knowledge and practice methods among individual participants.

2. The participants' specialty influenced their responses to both knowledge and clinical practice.

\section{Abbreviations}

RCT: Root canal treatment; PSP: Post space preparation; ETT: Endodontically treated teeth; GDP: General dental practitioner; PA: Periapical; EBD: Evidencebased dentistry.

\section{Supplementary Information}

The online version contains supplementary material available at https://doi. org/10.1186/s12903-021-01479-2.

Additional file 1. Sample of the questionnaire distributed to a number of Saudi dentists

\section{Acknowledgements}

The authors would like to thank the College of Dentistry Research Center and Deanship of Scientific Research at King Saud University, Saudi Arabia, to support this research project (research Project \# FR 0459).

\section{Authors' contributions}

Both authors listed in this manuscript have made substantial contributions to this study. RB and SB together conceived and designed the study and interpreted the results. RB contributed to data collection, and SB contributed to data analysis. RB and SB prepared and edited the manuscript and approved the final version.

\section{Funding}

Not Applicable. This research did not receive any specific grant from funding agencies in the public, commercial, or not-for-profit sectors.

\section{Availability of data and materials}

All data analyzed during this study are included in this published article. Additionally, the complete dataset supporting the conclusions of this article is available from the corresponding author and can be accessed upon a reasonable request.

\section{Declarations}

\section{Ethics approval and consent to participate}

Ethical approval was obtained from Institutional Review Board of King Saud University and the College of Dentistry Research Center and ethics committee with a ref. No.:E-18-3361, CDRC No.: FR 0459. The participants' rights were protected by ensuring voluntary participation and supported by written informed consent for participation in the study; after explaining the purpose, nature, time to conduct the study, the potential benefits and risks of the study and data collection techniques. The anonymity and confidentiality of the participants were assured and treated as strictly confidential. Furthermore, they were not required to mention their names and they were given a full right to drop from participating in the study.

\section{Consent for publication}

Not applicable.

\section{Competing interests}

The authors declare that there is no conflict of interest regarding the publication of the article. The content of this manuscript has not been presented previously nor submitted elsewhere.

\section{Author details \\ ${ }^{1}$ Department of Prosthetic Dental Sciences, College of Dentistry, King Saud University, Riyadh 12372, Saudi Arabia. ${ }^{2}$ Department of Restorative Dental Sciences, College of Dentistry, King Saud University, Riyadh, Saudi Arabia. ${ }^{3}$ Pre- sent Address: Division of Dentistry, Faculty of Biology, Medicine, and Health, School of Medical Sciences, University of Manchester, Manchester, UK.}

Received: 25 June 2020 Accepted: 3 March 2021

Published online: 10 March 2021

\section{References}

1. Baba N, Goodacre C, Al-Harbi F. Principles for restoration of endodontically treated teeth. Contemporary restoration of endodontically treated teeth: evidence-based diagnosis and treatment planning. Quintessence Publishing Co Inc; 2013. pp. 61-71.

2. Ricucci D, Russo J, Rutberg M, Burleson JA, Spangberg LS. A prospective cohort study of endodontic treatments of 1369 root canals: results after 5 years. Oral Surg Oral Med Oral Pathol Oral Radiol Endod. 2011;112(6):825-42.

3. Ng YL, Mann V, Rahbaran S, Lewsey J, Gulabivala K. Outcome of primary root canal treatment: systematic review of the literature-part 1. Effects of study characteristics on probability of success. Int Endod J. 2007;40(12):921-39.

4. Sorensen JA, Martinoff JT. Intracoronal reinforcement and coronal coverage: a study of endodontically treated teeth. J Prosthet Dent. 1984;51(6):780-4.

5. Stavropoulou AF, Koidis PT. A systematic review of single crowns on endodontically treated teeth. J Dent. 2007;35(10):761-7.

6. Eckerbom M, Magnusson T. Restoring endodontically treated teeth: a survey of current opinions among board-certified prosthodontists and general dental practitioners in Sweden. Int J Prosthodont. 2001;14(3):245-9.

7. Habib SR, Al Rifaiy MQ, Alkunain J, Alhasan M, Albahrani J. Concepts of restoring endodontically treated teeth among dentists in Saudi Arabia. Saudi J Dent Res. 2014;5(1):15-20.

8. Morgano SM, Bowley JF, Thalib L, Abdulkarim E. A survey of contemporary philosophies and techniques of restoring endodontically treated teeth in Kuwait. Med Princ Pract. 2001;10(1):14-22.

9. Naumann M, Neuhaus KW, Kolpin M, Seemann R. Why, when, and how general practitioners restore endodontically treated teeth: a representative survey in Germany. Clin Oral Investig. 2016;20(2):253-9.

10. Nawasrah A, Farooqi FA. Evaluating the basic knowledge and techniques of dentists about restoring endodontically treated teeth in Saudi Arabia. J Dent Oral Health. 2017:5:2.

11. Sabbak SA, Tulba H. A survey of contemporary methods of restoring endodontically treated teeth in Riyadh area-Part II: premolar teeth. Saudi Dent J. 2004;16:70-7.

12. Scurria MS, Shugars DA, Hayden WJ, Felton DA. General dentists' patterns of restoring endodontically treated teeth. J Am Dent Assoc. 1995;126(6):775-9.

13. Seow LL, Toh CG, Wilson NH. A survey of current practices among general dental practitioners in Manchester in 2002. Prim Dent Care. 2003;10(3):87-92

14. Song M, Park M, Lee CY, Kim E. Periapical status related to the quality of coronal restorations and root fillings in a Korean population. J Endod. 2014;40(2):182-6.

15. Majumdar SR, McAlister FA, Furberg CD. From knowledge to practice in chronic cardiovascular disease: a long and winding road. J Am Coll Cardiol. 2004:43(10):1738-42.

16. Afrashtehfar Kl, Assery MK. From dental science to clinical practice: knowledge translation and evidence-based dentistry principles. Saudi Dent J. 2017;29(3):83-92. 
17. Graham ID, Tetroe J. Some theoretical underpinnings of knowledge translation. Acad Emerg Med. 2007;14(11):936-41.

18. Al-Kahtani AM. The Saudi Dental Journal's mission for the Saudi Dental Society. Saudi Dent J. 2011;23(1):1.

19. McHugh ML. Interrater reliability: the kappa statistic. Biochem Med (Zagreb). 2012;22(3):276-82.

20. Khan SB, Chikte UM, Omar R. From classroom teaching to clinical practice: experiences of senior dental students regarding the shortened dental arch concept. J Dent Educ. 2014:78(6):906-13.

21. Wilder R, Robinson C, Jared HL, Lieff S, Boggess K. Obstetricians'knowledge and practice behaviors concerning periodontal health and preterm delivery and low birth weight. J Dent Hyg. 2007;81(4):81.

22. Graham ID, Logan J, Harrison MB, Straus SE, Tetroe J, Caswell W, et al. Lost in knowledge translation: time for a map? J Contin Educ Health Prof. 2006;26(1):13-24.

23. Adams AS, Soumerai SB, Lomas J, Ross-Degnan D. Evidence of selfreport bias in assessing adherence to guidelines. Int J Qual Health Care. 1999;11(3):187-92.

24. Pratt I, Aminoshariae A, Montagnese TA, Williams KA, Khalighinejad N, Mickel A. Eight-year retrospective study of the critical time lapse between root canal completion and crown placement: its influence on the survival of endodontically treated teeth. J Endod. 2016;42(11):1598-603.

25. Schwartz RS, Robbins JW. Post placement and restoration of endodontically treated teeth: a literature review. J Endod. 2004;30(5):289-301.

26. Metzger Z, Abramovitz R, Abramovitz I, Tagger M. Correlation between remaining length of root canal fillings after immediate post space preparation and coronal leakage. J Endod. 2000;26(12):724-8

27. Cabana MD, Rand CS, Powe NR, Wu AW, Wilson MH, Abboud PA, et al. Why don't physicians follow clinical practice guidelines? A framework for improvement. JAMA. 1999;282(15):1458-65.

28. Kortteisto T, Kaila M, Komulainen J, Mantyranta T, Rissanen P. Healthcare professionals' intentions to use clinical guidelines: a survey using the theory of planned behaviour. Implement Sci IS. 2010:5:51.

29. Bonetti D, Johnston M, Clarkson JE, Grimshaw J, Pitts NB, Eccles M, et al. Applying psychological theories to evidence-based clinical practice: identifying factors predictive of placing preventive fissure sealants. Implement Sci IS. 2010;5:25.

30. Balto HA, Al-Madi EM. A comparison of retreatment decisions among general dental practitioners and endodontists. J Dent Educ. 2004;68(8):872-9.

31. Basudan SO, Alghamdi SM, Alsultan HS. Effect of case diagnosis and professional training on endodontic irrigant selection. Saudi Endod J. 2018;8(3):196.

32. Abramovitz I, Tagger, M., Tamse, A., \& Metzger, Z. The effect of immediate vs. delayed post space preparation on the apical seal of a root canal filling: a study in an increased-sensitivity pressure-driven system. J Endod. 2000;26(8):435-9.
33. Haddix JE, Mattison GD, Shulman CA, Pink FE. Post preparation techniques and their effect on the apical seal. J Prosthet Dent. 1990;64(5):515-9.

34. Ørstavik D. Time-course and risk analyses of the development and healing of chronic apical periodontitis in man. Int Endod J. 1996;29:150-5.

35. Fristad IMO, Halse A. Nonsurgically retreated root filled teeth-radiographic findings after 20-27 years. Int Endod J. 2004;37:12-8.

36. Yee K, Bhagavatula P, Stover S, Eichmiller F, Hashimoto L, MacDonald S, et al. Survival rates of teeth with primary endodontic treatment after core/post and crown placement. J Endod. 2018;44(2):220-5.

37. Gomes AC, Nejaim Y, Silva Al, Haiter-Neto F, Cohenca N, Zaia AA, et al. Influence of endodontic treatment and coronal restoration on status of periapical tissues: a cone-beam computed tomographic study. J Endod. 2015;41(10):1614-8

38. Moreno JO, Alves FR, Goncalves LS, Martinez AM, Rocas IN, Siqueira JF Jr. Periradicular status and quality of root canal fillings and coronal restorations in an urban Colombian population. J Endod. 2013;39(5):600-4.

39. Aquilino SA, Caplan DJ. Relationship between crown placement and the survival of endodontically treated teeth. J Prosthet Dent. 2002;87(3):256-63

40. Goldfein J, Speirs C, Finkelman M, Amato R. Rubber dam use during post placement influences the success of root canal-treated teeth. J Endod. 2013;39(12):1481-4

41. Baba NZ, Goodacre CJ. Restoration of endodontically treated teeth: contemporary concepts and future perspectives. Endod Top. 2014;31(1):86-93.

42. Baldissara P, Comin G, Martone F, Scotti R. Comparative study of the marginal microleakage of six cements in fixed provisional crowns. J Prosthet Dent. 1998;80(4):417-22.

43. Alves de Carvalho IF, Santos Marques TM, Araujo FM, Azevedo LF, Donato H, Correia A. Clinical performance of CAD/CAM tooth-supported ceramic restorations: a systematic review. Int J Periodontics Restor Dent. 2018;38(4):e68-78.

44. Moghaddam AS, Radafshar G, Taramsari M, Darabi F. Long-term survival rate of teeth receiving multidisciplinary endodontic, periodontal and prosthodontic treatments. J Oral Rehabil. 2014;41 (3):236-42.

45. AlBaker AA, Al-Ruthia YSH, AlShehri M, Alshuwairikh S. The characteristics and distribution of dentist workforce in Saudi Arabia: a descriptive cross-sectional study. Saudi Pharm J SPJ Off Publ Saudi Pharm Soc. 2017;25(8):1208-16.

\section{Publisher's Note}

Springer Nature remains neutral with regard to jurisdictional claims in published maps and institutional affiliations.

Ready to submit your research? Choose BMC and benefit from:

- fast, convenient online submission

- thorough peer review by experienced researchers in your field

- rapid publication on acceptance

- support for research data, including large and complex data types

- gold Open Access which fosters wider collaboration and increased citations

- maximum visibility for your research: over $100 \mathrm{M}$ website views per year

At BMC, research is always in progress.

Learn more biomedcentral.com/submissions 